\title{
Spontaneous Anterior Thoracic Spinal Cord Herniation through Dura Defect: A Case Report
}

\author{
Kyung-Ho Jeong, Hyun-Woo Lee, Young-Min Kwon \\ Department of Neurosurgery, Dong-A University College of Medicine, Busan, Korea
}

\begin{abstract}
Thoracic spinal cord herniation is a rare disease cause of progressive myelopathy. Magnetic resonance image is a useful tool to diagnose preoperatively. Operation is a treatment of option. Sixty-six-year-old female visited Dong-A University Medical Center for progressive gait disturbance with falling tendency to right side. She had radiating pain and tingling sense on both leg. Sense of touch and temperature was decreased below T6 level. Both hip and knee motor power were grade IV. Magnetic resonance imaging scan showed anterior displacement of the spinal cord at T4-T5 vertebral level. Under the diagnosis of thoracic spinal cord herniation with dura defect, operation was performed for the patient with intraoperative neuromonitoring. Laminectomy at T4 and T5 level was done, and intradural exploration of the spinal cord revealed dura defect about $25 \mathrm{~mm} \times 8 \mathrm{~mm}$ in size. Spinal cord was released under microscope and dura defect was repaired with Lyoplant. The patient's symptom improved after the surgical procedure, but touch and temperature sense under T6 level had unchanged.
\end{abstract}

Key Words: Spinal cord $\cdot$ Hernia $\cdot$ Thorax $\cdot$ Paraparesis

\section{INTRODUCTION}

It is extremely rare for the spinal cord displaced out of the dura through a dural defect, which is known as a spinal cord herniation $(\mathrm{SCH})$. The classification of the $\mathrm{SCH}$ is known as traumatic, iatrogenic, and idiopathic according to the causes of dura defect ${ }^{6}$. Among those, the idiopathic SCH is one of even rarer causes of progressive myelopathy ${ }^{3,4,7}$. Usual symptoms contain progressive sensorimotor Brown-Sequard-like syndrome ${ }^{9}$. Surgical treatment of $\mathrm{SCH}$ is usually followed by stabilization or improvement in the neurological symptoms, but still unfavorable postoperative outcomes are also reported ${ }^{33}$. The release of the herniated portion of the spinal cord and subsequent repositioning of the cord into the normal anatomic position is advocated as essential. Several surgical methods are introduced, such as patch closure after enlargement of the ventral dura defect and closure of the defect by direct suture ${ }^{1,2)}$. We treated a patient with spontaneous herniation of the midthoracic spinal cord through a dura defect manifesting paraparetic movement with decreased proprioception and sensory change.

- Received: October 20, 2015 • Revised: February 23, 2016

- Accepted: February 24, 2016

Corresponding Author: Young-Min Kwon

Department of Neurosurgery, Dong-A University Hospital, Dong-A

University College of Medicine, 26 Daesingongwon-ro, Seo-gu, Busan 49201, Korea

Tel: +82-51-240-5241, Fax: +82-51-242-6714

E-mail: ymkwon@dau.ac.kr

$\otimes$ This is an open access article distributed under the terms of the Creative Commons Attribution Non-Commercial License (http://creativecommons.org/licenses/by-nc/4.0/) which permits unrestricted non-commercial use, distribution, and reproduction in any medium, provided the original work is properly cited.

\section{CASE REPORT}

A 66-year-old female presented paraparesis with progressive gait disturbance and falling tendency to right side for 3 years. She had radiating pain and tingling sense on both legs. The motor weakness had slowly been aggravated over 6 months. She had been taking medications for primary hypertension and hypothyroidism. Posterior lumbar interbody fusion at $\mathrm{L} 4 / 5$ was done 3 years before visitation. No other trauma or surgical history was identified.

Both sides of her quadriceps muscles and hamstring groups were atrophic, and unhealed scar on her right anterior lower leg was identified due to repeated fall. Both hip and knee motor powers were grade IV with neurogenic claudication. Both knee and ankle jerk were exaggerated without Babinski reflexes. Sense of touch and temperature was decreased below T6 level. No evidence of bowl or bladder dysfunction was confirmed. Simple $\mathrm{X}$-ray showed no abnormal finding. Magnetic resonance imaging (MRI) scan revealed anterior displacement of the spinal cord at T4-T5 vertebral level (Fig. 1). The diagnosis was spontaneous anterior thoracic $\mathrm{SCH}$ with dura defect.

Posterior approach was performed with intraoperative neuromonitoring for careful procedure. Bilateral laminectomy was done at T4-T5 levels to expose dorsal dura. Linear incision of dura was done for retraction of spinal cord. Intradural exploration of the spinal cord revealed dura defect about $25 \mathrm{~mm} \times$ $8 \mathrm{~mm}$ in size (Fig. 2A). No abnormality such as cystic or inflammatory lesion was found. Spinal cord was fully released under microscope and dura defect was sealed with Lyoplant (Aesculap Inc., Philadelphia, PA, USA) (Fig. 2B). Afterwards, the dorsal durotomy was closed primarily. 


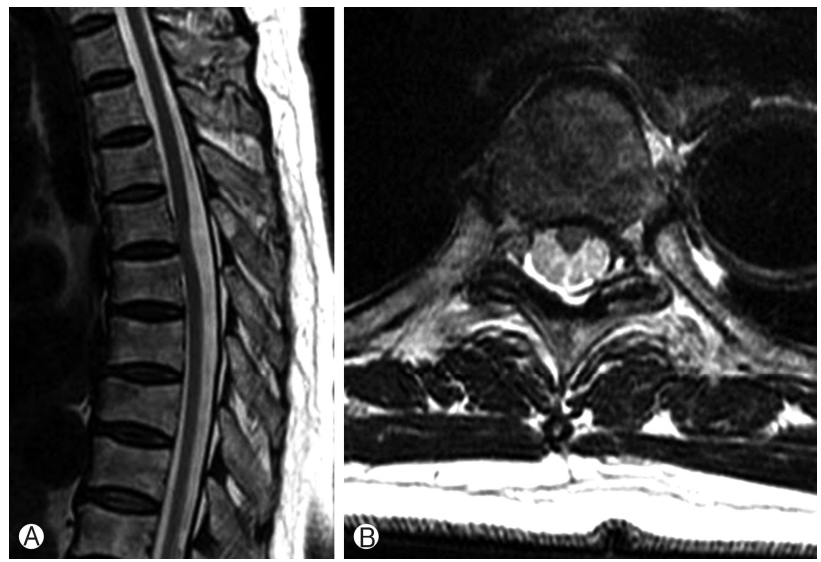

Fig. 1. T2 sagittal (A) and axial (B) images of thoracic spinal cord herniation. Spinal cord shows herniation to left anterior portion at $\mathrm{T} 4 / 5$ disc level.
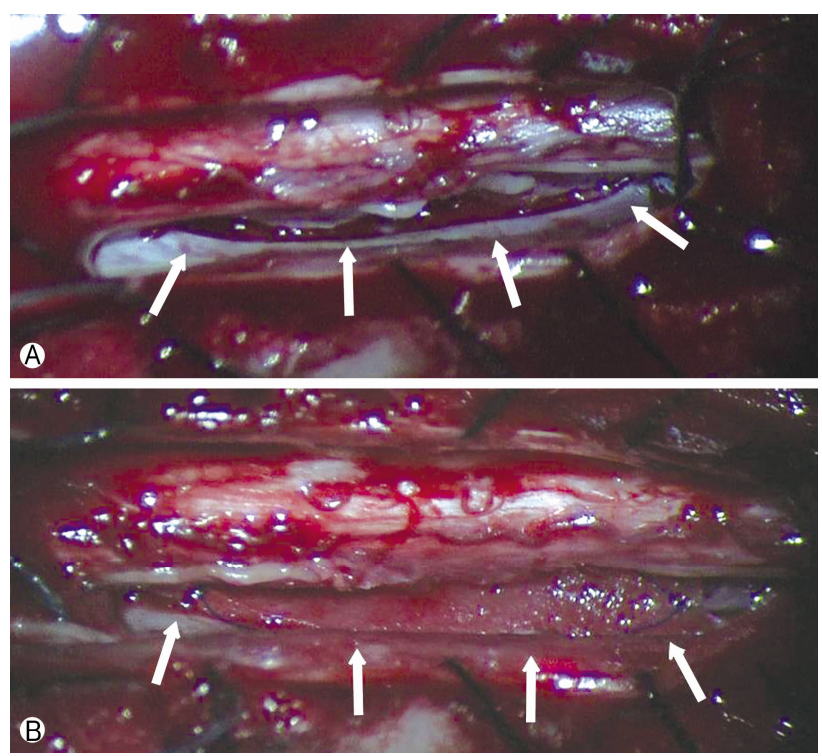

Fig. 2. (A) Intraoperative microscopic image shows dura defect (white arrows) $25 \mathrm{~mm} \times 8 \mathrm{~mm}$ in size at the left anterior portion of spinal cord. (B) Dura defect was directly repaired with Lyoplant (Aesculap Inc., Philadelphia, PA, USA) (white arrows).

Gait disturbance and motor power improved to nearly normal state 3 days after operation, so as radiating pain on both legs. Neurogenic claudication also improved from 5 to $50 \mathrm{~m}$, but touch and temperature sense under T6 level had been unchanged.

\section{DISCUSSION}

Among several different types of SCHs, spontaneous $\mathrm{SCH}$, which is an extremely rare disease, was firstly introduced by Wortzman et al. ${ }^{10)}$, and increasing number of cases have been reported since then. Middle aged-women have more tendencies to have the disease in the third and eighth thoracic level ${ }^{2)}$. The patient of our case report was in middle age and had shown cord herniation with dura defect at T4-T5 level, which certainly matches with the characteristic of the disease epidemiology.

Theoretically, the microscopic erosion of dural surface caused by repeated flexion and extension; secondary dural damage due to arachnoid cyst or other congenital diseases; or inflammatory change of dura by herniated discs could result in the incarceration of spinal cord, yet the pathophysiology of the formation of dural defect is still not clarified ${ }^{1)}$. In addition, thoracic SCH could be closely related to the cardiopulmonary movements which cause the tissue adhesions or inflammatory reactions around the thoracic cord, so that it could finally lead to progressive pathological alteration of thoracic spinal cord ${ }^{1,8)}$. In our case, the dura defect located at the disc level of thoracic spine with clean margin, from which could be assumed that the defect could be formed spontaneously by degenerative change.

According to Groen et al. ${ }^{2}$, , progressive Brown-Sequard-like syndrome was present in 66\% and paraparesis in 30\% among 129 cases of anterior thoracic SCH patients. The $75.9 \%$ of the patients with Brown-Sequard syndrome showed improvement after surgical treatment while only $55 \%$ of the paraparetic patients improved ${ }^{2}$. Most of the patients showed progressive aggravation of the symptom, so eventually it led to the surgical treatment. The mean operative interval was 5.2 years while our patient suffered from the progressive paraparetic symptom with defect of proprioception for 3 years before treatment, which had improved three days after the surgery.

Diagnostic incidence has been increasing due to the development of MRI. The displacement of spinal cord through dural defect could be confirmed at either T1 or T2 weight images. It could also be diagnosed with MRI showing transdural cord herniation at T4/5 disc level in left anterior potion of dura in our case. No other radiologic evaluation was done for our patient except for simple X-ray of thoracic spine. Additionally, computed tomography (CT) myelogram or simple CT also could help clarify the presence of cystic mass ${ }^{1)}$.

Surgical procedures introduced so far are the closure of dura defect by direct suture ${ }^{2,5)}$ and the filling the dura defect by flat graft ${ }^{5,7)}$. Direct closure is considered to be necessary to prevent postoperative cerebrospinal fluid collection and achieve realignment of spinal cord. Also, promoters of this strategy state the effective prevention of recurrence of $\mathrm{SCH}$. On the other hand, using graft technique is believed to be safer and shows better outcome because of less cord manipulation than direct suture during operation. Both methods contain cord decompression through dura resection of the defected area. The patient in this case had relatively large size of dura defect with $25 \mathrm{~mm} \times 8 \mathrm{~mm}$ at the anterior portion of the spinal cord, so the graft technique was preferred because the overmanipulation of the spinal cord would be inevitable when directly sutured. 
Because the incidence rate of the diagnosis of spontaneous anterior thoracic cord herniation has been increasing due to the frequent use of MRI as diagnostic method, there would be more chance of encountering cord herniation patient of when diagnosing patients. Moreover, most of the patients with surgical procedure showed satisfying results, which leads us to take surgical treatment into account when we encounter the patient with $\mathrm{SCH}^{2}$.

\section{CONCLUSION}

Patients showing myelopathic symptoms such as BrownSequard-like or paraparetic movements without traumatic events should be differentially diagnosed with $\mathrm{SCH}$. Even though it is known to be rare, when a patient is diagnosed with the spontaneous anterior thoracic $\mathrm{SCH}$, a surgical approach could be considered as a primary treatment.

\section{CONFLCT OF INTEREST}

No potential conflict of interest relevant to this article was reported.

\section{REFERENCES}

1. Cho JY, Rhim SC, Jeon SR, Roh SW: Ventral transdural spinal cord herniation: case report and review of the literature. Korean J Spine 3:246-249, 2006

2. Groen RJ, Middel B, Meilof JF, de Vos-van de Biezenbos JB, Enting RH, Coppes $\mathrm{MH}$, et al: Operative treatment of anterior thoracic spinal cord herniation: three new cases and an individual patient data meta-analysis of 126 case reports. Neurosurgery 64(3 Suppl):ons145-159, 2009

3. Hausmann ON, Moseley IF: Idiopathic dural herniation of the thoracic spinal cord. Neuroradiology 38:503-510, 1996

4. Hawasli AH, Ray WZ, Wright NM: Symptomatic thoracic spinal cord herniation: case series and technical report. Neurosurgery 10(Suppl 3):E498-504, 2014

5. Inoue T, Cohen-Gadol AA, Krauss WE: Low-pressure headaches and spinal cord herniation. Case report. J Neurosurg 98(1 Suppl): 93-95, 2003

6. Kumar R, Taha J, Greiner AL: Herniation of the spinal cord. Case report. J Neurosurg 82:131-136, 1995

7. Maira G, Denaro L, Doglietto F, Mangiola A, Colosimo C: Idiopathic spinal cord herniation: diagnostic, surgical, and follow-up data obtained in five cases. J Neurosurg Spine 4:10-19, 2006

8. Marshman LA, Hardwidge C, Ford-Dunn SC, Olney JS: Idiopathic spinal cord herniation: case report and review of the literature. Neurosurgery 44:1129-1133, 1999

9. Najjar MW, Baeesa SS, Lingawi SS: Idiopathic spinal cord herniation: a new theory of pathogenesis. Surg Neurol 62:161-170, 2004

10. Wortzman G, Tasker RR, Rewcastle NB, Richardson JC, Pearson FG: Spontaneous incarcerated herniation of the spinal cord into a vertebral body: a unique cause of paraplegia. Case report. J Neurosurg 41:631-635, 1974 